\title{
Correction to: The inherent link between ore formation and geometallurgy as documented by complex tin mineralization at the Hämmerlein deposit (Erzgebirge, Germany)
}

\author{
Marius Kern $^{1}$ (D) Julian Kästner ${ }^{1,2} \cdot$ Raimon Tolosana-Delgado $^{1} \cdot$ Tilman Jeske $^{2} \cdot$ Jens Gutzmer $^{1}$
}

Received: 4 March 2019 / Accepted: 5 March 2019 / Published online: 22 March 2019

(C) Springer-Verlag GmbH Germany, part of Springer Nature 2019

\section{Erratum to: Mineralium Deposita} https://doi.org/10.1007/s00126-018-0832-2

We noticed that the presented formula for calculation of the MAMA ratio requires clarification in two places.

(1) The formula for the MAMA ratio as it appears in the original version of the manuscript

MAMA $_{\text {target }}=\alpha \frac{\text { Mineral Association }\left(\operatorname{Min}_{X}\right) \text { with target mineral }}{\text { Mineral Area }\left(\operatorname{Min}_{X}\right)}$

suggests to the reader to use absolute values for Mineral Area $\left(\operatorname{Min}_{X}\right)$. Instead, relative values were used to calculate the MAMA ratio. We would like to correct the formula to

MAMA $_{\text {target }}=\alpha \frac{\text { Mineral Association }\left(\operatorname{Min}_{X}\right) \text { with target mineral }}{\text { Mineral Area }(\%)\left(\operatorname{Min}_{X}\right)}$

Editorial handling: B. Lehmann

The online version of the original article can be found at https://doi.org/ 10.1007/s00126-018-0832-2

Marius Kern

m.kern@hzdr.de

1 Helmholtz-Zentrum Dresden-Rossendorf, Helmholtz Institute Freiberg for Resource Technology, Chemnitzer Straße 40, 09599 Freiberg, Germany

2 Institute of Mineralogy, Technische Universität Bergakademie Freiberg, Brennhausgasse 14, 09599 Freiberg, Germany
(2) Normalization of MAMA target values with $\alpha$ may be a justifiable step when comparing between datasets from different sampling locations. However, we generally recommend choosing a value of $\alpha=1$ when there are no clear indications that such normalization is necessary.

An example - where cassiterite is the target mineral and chlorite is $\operatorname{Min}_{X}$ - may further help to clarify the MAMA formula: The length of the grain boundaries between chlorite and cassiterite in a given slab measured is $X \mathrm{~mm}$. The total length of the grain boundaries of chlorite with all minerals is $Y \mathrm{~mm}$. The mineral association value is then $X / Y$. This value is normalized to the area fraction of chlorite in the sample, which gives the dimensionless MAMA ratio.

We would like to thank Dr. Max Frenzel from HelmholtzZentrum Dresden-Rossendorf, who informed us about the discrepancies.

Publisher's note Springer Nature remains neutral with regard to jurisdictional claims in published maps and institutional affiliations. 